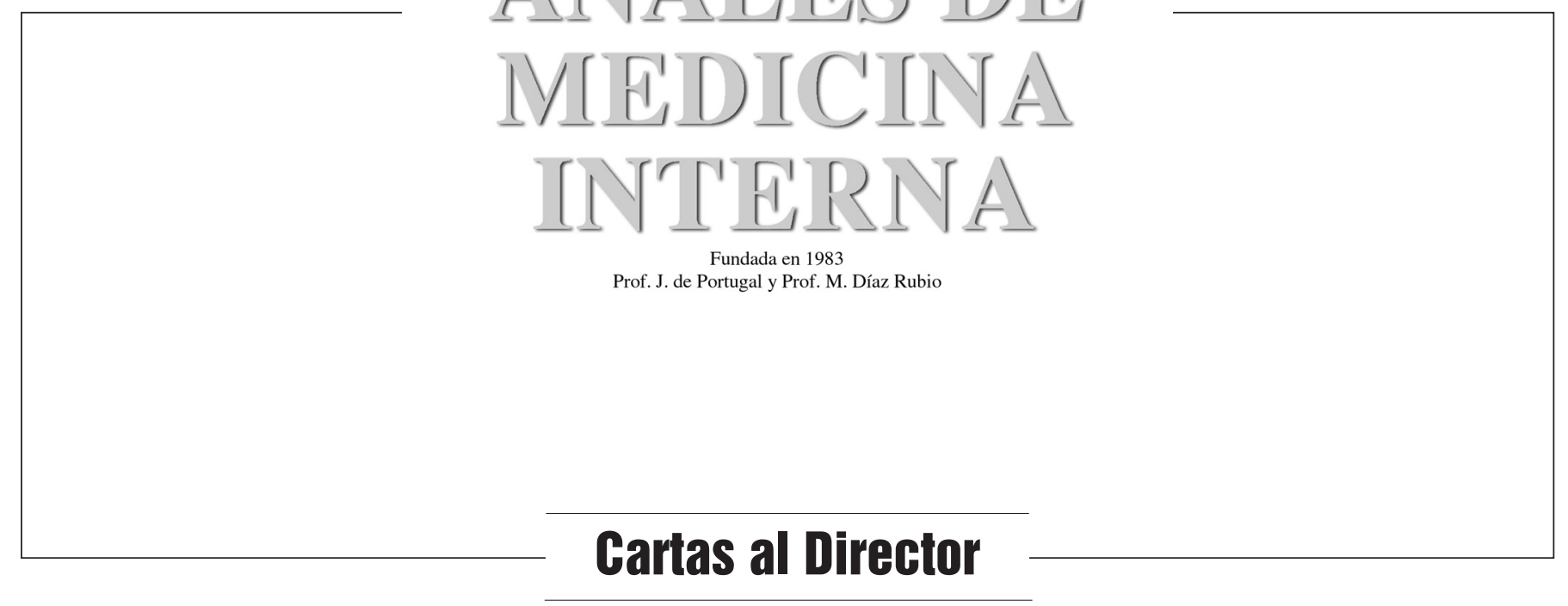

\section{Muertes causadas por problemas hospitalarios}

\section{Sr. Director:}

La mortalidad hospitalaria es uno de los indicadores de calidad asistencial más utilizado, su análisis puede utilizarse como un valioso instrumento para la planificación y la gestión hospitalaria, la cuantificación de las defunciones hospitalarias puede considerarse como una medida de efectividad de la intervención hospitalaria (1).

En la literatura el análisis de la mortalidad se inicia en 1976 con Rutsein D, que publicó un listado de afecciones en las que había evidencia científica, que era posible evitar la enfermedad,incapacidad y/o muerte, con los medios sanitarios disponibles ya sea a través del tratamiento o la prevención.

La Health Care Financing Administration en los años 80 incorpora el análisis del porcentaje de mortalidad hospitalaria para la comparación cualitativa de los hospitales americanos y desde entonces se han publicado diversos estudios en este sentido, y todos ellos concluyen la necesidad de ajustar la mortalidad a otros parámetros.

Es conocido que la revisión de historias clínicas detecta posibles déficits en la asistencia y el realizar el análisis de los efectos adversos de la atención médica revitaliza el concepto de muerte evitable y algunas de las estrategias que Rutsein ya formuló.

Los efectos adversos debidos a la intervención sanitaria son considerados como aquellos que ocasionan algún tipo de discapacidad ya sea reversible o permanente (2). La literatura muestra que se utiliza diferente terminología para expresar una misma idea, así podemos encontrar: complicaciones, yatrogenia, efectos adversos, patología nosocomial o problemas hospitalarios. Además los criterios de inclusión de cada estudio son diferentes incluso utilizando palabras iguales.

El objetivo fue revisar los éxitus secundarios a problemas hospitalarios (ESPHs) en los últimos 6 años en un Servicio de Medicina Interna, agrupándolos en 5 categorías: a) infección nosocomial; según la definición del Center Diseases Control (CDC); b) técnica diagnóstica/terapéutica;cuando la causa de muerte está directamente relacionada con la ejecución de una decisión diagnóstica o terapéutica; c) omisión de tratamiento/profilaxis;no proporcionar o demorar un tratamiento o profilaxis de demostrada eficacia, ya sea por error diagnóstico o desconocimiento; d) incidente nocivo; hechos inesperados que pueden suceder en un hospital y que pueden conducir a la muerte del paciente como por ejemplo las aspiraciones o caídas; y e) problema organizativo/estructural;cuando la muerte se puede atribuir directamente a un déficit organizativo o de estructura, por ejemplo un desfibrilador que no funcione.

Los grandes avances tecnológicos de los que se dispone actualmente, no han proporcionado una disminución de la morbimortalidad. Es indiscutible que la aplicación de sistemas de evaluación en los centros hospitalarios, pueden ayudar a detectar problemas y a mejorar la calidad asistencial.

La tasa global de ESPH calculada como el cociente entre número de ESPHs y número d'altas, en nuestro servicio fue del $0,6 \%$ algo superior a los objetivos recomendados,siendo similar a otras series (delrio), sin olvidar que esta última es una tasa hospitalaria y no exclusiva o ajustada a un Servicio de Medicina Interna.

\begin{tabular}{lcccccccc}
\multicolumn{10}{c}{ TABLA I } \\
\hline ESHP & 1997 & 1998 & 1999 & 2000 & 2001 & 2002 & 2003 & 2004 \\
Infección nosocomial & $2(16,6)$ & $5(33,3)$ & $8(50)$ & $12(92,3)$ & $5(45,4)$ & $9(50)$ & $6(35,2)$ & $2(11,7)$ \\
Técnica terapéutica & $3(25)$ & $3(20)$ & $3(18,7)$ & $1(7,6)$ & $3(27,2)$ & $2(11,1)$ & $2(11,7)$ & $2(11,7)$ \\
Omisión/Demora tratamiento & $5(41,6)$ & $2(13,3)$ & $1(6,25)$ & 0 & 0 & $2(11,1)$ & $6(35,2)$ & $9(52,9)$ \\
Incidente nocivo & $2(16,6)$ & $5(33,3)$ & $4(25)$ & 0 & $3(27,2)$ & $4(22,2)$ & $3(17,6)$ & $4(23,6)$ \\
Organizativo/estructural & $5(41,6)$ & 0 & 0 & 0 & 0 & $1(5,5)$ & 0 & $1(5,6)$ \\
\hline
\end{tabular}


Respecto a la distribución de los diferentes ESPHs detectados, es similar a lo publicado en la literatura, destacando en primer lugar la infección nosocomial (Tabla I) a expensas principalmente de la pneumonia. La estancia media hospitalaria de los ESPHs fue superior a la del resto de éxitus con una diferencia estadísticamente significativa $\mathrm{p}<0,0001$, con un rango de 0 a 61 días. $\mathrm{El}$ ESPH se produjo con más frecuencia en el sexo masculino independientemente de la patología asociada durante o previa al ingreso con una $\mathrm{p}<0,001$. La edad no influyó a la hora de presentar un ESPH.

El sistema de detección y análisis de ESPHs es objetivo y un buen sistema de trabajo que además sirve para instaurar un sistema de vigilancia de los problemas asistenciales que inciden directamente sobre la muerte de los pacientes. Serían precisos más estudios para poder corroborar la utilidad de los ESPHs como indicador de calidad y poder generalizar su utilización.

\section{Sanclemente Ansó, D. Pañella Mora, J. Vilaró Pujals}

Servicio de Medicina Interna. Hospital General de Vic. Barcelona

1. Sanclemente C, Barcons M, Moleiro MA, Alonso F, Pañella D, Carrera $\mathrm{R}$, et al. Mortalidad hospitalaria en un Servicio de Medicina Interna. An Med Interna (Madrid) 2004; 21: 317-21.

2. Brennan TA, Localio AR, Leape LL, Laird NM, Peterson L, Hiatt HH, et al. Identification of adverse events occurring during hospitalization. A cross-sectional study of litigation, quality assurance, and medical records at two teaching hospitals. Ann Intern Med 1990; 112: 221-6.

\section{Neumomediastino y enfisema subcutáneo como manifestación de una perforación duodenal}

\section{Sr. Director:}

El neumomediastino y enfisema subcutáneo esta causado en la mayoría de ocasiones por patología de origen respiratorio (1). Excepcionalmente, el neumomediastino representa el signo de debut de patología abdominal. En estos casos suele ir asociado a mal pronóstico (2) debido fundamentalmente al retraso diagnóstico dado que no se sospecha el origen abdominal. Presentamos un paciente con una perforación duodenal, que se acompañó de neumomediastino y enfisema subcutáneo, con buena evolución tras el tratamiento quirúrgico.

Varón de 48 años de edad en tratamiento con antiácidos por ulcus gastroduodenal, que consultó por cuadro de dolor abdominal epigástrico tipo continuo e inicio larvado de cuatro horas de evolución asociado a dos episodios de vómitos alimenticios, con ritmo gastrointestinal conservado, sin fiebre ni otra sintomatología acompañante. A la exploración física estaba consciente y orientado, con buen estado general, auscultación cardio-pulmonar normal y abdomen blando y depresible doloroso levemente a la palpación en epigastrio sin defensa ni signos de irritación peritoneal. En la analítica destacaba la presencia de 14.600 leucocitos con $80 \%$ de neutrófilos. La radiografía de tórax mostró un enfisema mediastínico con una lengüeta de aire que rodeaba la silueta cardiaca, siendo la radiografía de abdomen normal. El paciente quedó en observación en urgencias presentando a las 6 horas de forma brusca un gran enfisema subcutáneo en cara anterior de tórax y en región cervicofacial, asociado a aumento del dolor abdominal en epigastrio. La nueva radiografía de tórax confirmó los hallazgos previos y la existencia de un neumoperitoneo no existente previamente (Fig. 1).

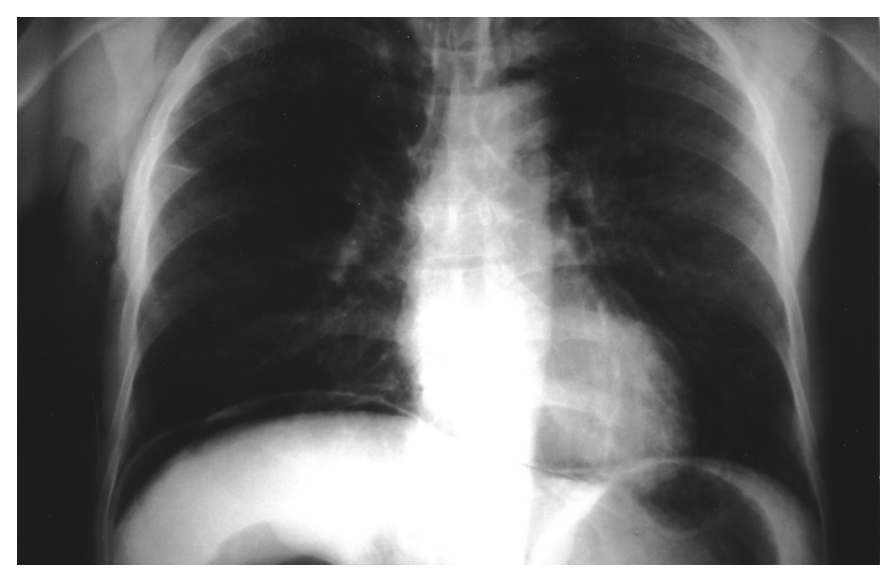

Fig. 1. Rx tórax: Presencia de enfisema mediastínico, subcutáneo y neumoperitoneo.

Con el diagnóstico de perforación de víscera hueca se intervino de urgencia mediante laparotomía media hallando cicatriz ulcerosa en región pilórica y perforación de cara posterolateral de segunda porción duodenal, realizando cierre mediante sutura simple a puntos sueltos y lavado de cavidad. El paciente evolucionó favorablemente sin complicaciones postquirúrgicas y fue dado de alta a los 10 días con tratamiento erradicador del Helicobacter Pylori.

El neumomediastino y enfisema subcutáneo está causado en la mayoría de ocasiones por patología de origen respiratorio1, aunque también se ha asociado a otros procesos 1 como ventilación mecánica, procesos anestésicos, extracciones dentarias, fracturas faciales, perforaciones esofágicas y más recientemente se han descrito casos secundarios a perforaciones gastroscópicas (3) o procedimientos quirúrgicos laparoscópicos abdominales (4). Excepcionalmente las úlceras gastroduodenales son causa de neumomediastino y enfisema subcutáneo (5-7) como nuestro caso clínico.

Los mecanismos a través de los cuales el aire difunde al mediastino o produce enfisema subcutáneo no están aun bien aclarados. Inicialmente se postuló que el aire de la cavidad abdominal podría difundir por gradiente de presión a través del peritoneo parietal, siendo un factor favorecedor la existencia de reacción inflamatoria peritoneal producida por la propia perforación (8), o bien el paso del aire a través de pequeños defectos congénitos del propio peritoneo9. Sin embargo, nos parece más razonable que en casos de una perforación duodenal a retroperitoneo como ocurrió en nuestro paciente, el aire difunda por el propio retroperitoneo y a través del hiato aórtico y/o esofágico hacia el mediastino como han propuesto otros autores $(7,9)$.

A nivel diagnóstico, no existen referencias claras en la literatura sobre las exploraciones complementarias necesarias para llevar a cabo un diagnóstico precoz. Nosotros creemos fundamental el realizar una anamnesis exhaustiva que nos permita una sospecha precoz de esta patología. Así mismo, pensamos que la TAC es la prueba diagnóstica de elección (10) ya que permite visualizar la existencia de neumoperitoneos de pequeño tamaño no detectados en ocasiones por la radiología simple, la existencia de líquido libre en cavidad peritoneal, o lo que es más importante, la presencia de 